immense difficulty and surely new concepts will be needed before we shall understand the balances that are at present symbolized by the 'ego', 'id' and 'super-ego' of the psychiatrists. This is a further area where a more developed biology should have much to give to our general understanding of 'belief' and its influence in our affairs.

Creeds are so important in determining our actions that any study of them is welcome. Waddington has faith that by learning what he calls "biological wisdom" we shall help mankind to survive. It is difficult to deny that if we had the necessary knowledge, based on study of ourselves and other creatures, we should be in a much stronger position. His book will encourage biologists, and one hopes others, to join in the search for a system of biology that is worthy to take its proper leading place in the guidance of human affairs.

J. Z. YOUNG

\section{THE FOURTH STATE OF MATTER}

\section{Plasma Physics}

By J. G. Linhart. (Series in Physics.) Pp. $x i+278$. (Amsterdam: North-Holland Publishing Company; New York: Interscience Publishers, Inc., 1960.) 508.

FEW years ago there was a shock-like wave of enthusiasm for plasma physics, 'plasma' being the name given by Irving Langmuir to ionized gases in which electrostatic effects maintain near equality between the densities of positive and negative charges. The rapid growth of the subject and interest in it has been followed by a more gradual wave of books, the one under review being one of the first to be published. It begins by remarking that plasma is the fourth state of matter, and that 99.9 per cent of the matter in the universe is in the plasma state. It is, indeed, likely that space research will make substantial contributions to the fundamentals of plasma physics, but this book is concerned mainly with theory, with two chapters on laboratory devices, particularly with a view to controlled thermonuclear fusion reactors.

The quality of the book is uneven, and some sections are not essential to plasma physics. For example, the first section is stated to be of more interest in electron optics and quite a lot of space is devoted to relativistic systems, which so far occur only in Christofilos's Astron. The whole first chapter on the motion of single particles in electromagnetic fields suffers from an intrusion of accelerator physics, not surprising for a book written at CERN, but it is unfortunate that equation (100) is reached with very little plasma yet seen. The last section of this chapter is very useful in collecting together accounts of bremsstrahlung, "cyclotron (betatron, synchrotron) radiation' and Cerenkov radiation.

After some Hamiltonian mechanics, moments of the Boltzmann equation are taken in Chapter 2. A major criticism here is that there is not even a qualitative discussion of the effects of collisions, distasteful as they may be; they are left until the last of the theory chapters. Chapter 2 ends with the hydromagnetic equations, but without mentioning viscosity. Chapter 3 is a useful account of equilibrium configurations, including most of those used in thermonuclear experiments. Chapter 4 deals with longitudinal, radio and hydromagnetic waves in a straightforward and clear manner. Landau damping is discussed in terms of diffusion (referring forward to the chapter on collisions) rather than in terms of particle trapping, and damping by collisions is not discussed. The chapter ends with a well-illustrated section on instabilities, a branch of the subject which now occupies a dominating position. Chapter 5 on shocks is not so clear. A typical Z-pinch experiment and plasmoids are included.

Chapter 6 deals with collisions. Use of the Debye length as cut-off distance is justified as due to screening-a common fallacy; the true justification involves thermal fluctuations. The Fokker-Planck equation is introduced early on, and used for electrical conduction, including a good account of runaways. Other transport coefficients are dealt with by cruder methods which are not so well explained. There is confusion between a diffusion constant and the speed of a wave, and it is stated that viscosity causes turbulence.

Chapter 7 outlines attempts at controlled fusion. and Chapter 8 other applications.

This book has undoubtedly been valuable to many people already, but is now meeting stiff competition. J. W. DUNGEY

\section{NATURE IN PICTURES}

\section{The Wonderful World of Nature}

Fauna and Flora in 300 Pictures. By F. A. Roedelberger and 60 Wild Life Photographers. English version by Mary Phillips. Pp. iv +214. (London: Constable and Co., Ltd.; New York: Viking Press, Inc.; Toronto: Longmans, Green and Co., 1961.) $32 s .6 d$. net.

THIS is a fascinating book. It is an English version of the Swiss original, containing several hundred pictures of wild life, taken by sixty famous photographers.

Most kinds of life are included: birds, fish, reptiles, mammals, small animals, insects, plants, fungi and flowers. The pictures speak for themselves by portraying both ordinary and poignant events in the life of each. Every page reveals the truth, whether beautiful (as the picture of edelweiss growing on a mountain precipice), essential (as a linnet foeding its hungry brood) or harsh (as a stoat attacking a rabbit's throat).

These pictures capture the interest, bringing to those unable to enjoy wild life at first hand a sense of the freshness of open countryside and the stillness of the forest or water's edge. They can also offer something to those who are more fortunate and able to take advantage of these pleasures: they can provide glimpses rare even to seasoned naturalistsfor example, a battle between a green lizard and viper.

Most of the photographs are black and white, but there are twenty-four excellent full-page colour pictures.

To complement the pictures, there is a comparatively small amount of text. Nevertheless, plenty of information can be gained from reading, and many 'titbits' of information add to the enjoyment.

There is no particular sequence, nor is the book subdivided in any way. However, this does not seem any disadvantage to a delightful book, beautifully presented.

It is gratifying to learn that the publishers have decided to present a portion of the profits on the sales of this book to the World Wild Life Fund. 